\title{
Is a Specialised Training of Phonological Awareness Indicated in Every Preschool Child?
}

\author{
Annerose Keilmann ${ }^{a}$ Monika Wintermeyer ${ }^{b}$

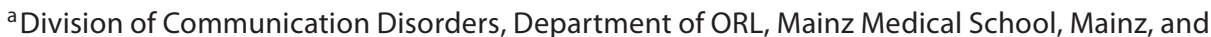 \\ ${ }^{b}$ Division of Education, University of Frankfurt, Frankfurt, Germany
}

\section{Key Words}

Phonological awareness - Dyslexia, prevention •

Specific training $\cdot$ Hearing disorder

\begin{abstract}
Objective and Methods: In a prospective study 218 preschool children were enrolled (stratified in 2 training programs, one specialized for phonologic awareness in order to prevent dyslexia, the other consisting in training of general perception) during the last year of kindergarten. After finishing the first grade 131 children were compared in their reading and writing abilities. Results: In the whole group only a slight difference was found between both training modalities concerning their writing abilities. However, children with a history of hearing loss, actual hearing loss or pathologic middle ear findings profited most from the specialized training program compared to the control in their reading abilities. Conclusion: A specialized training program to improve phonologic awareness as a basis for reading and writing in every kindergarten and preschool child seems to be unnecessary. However, children with temporary hearing deficits benefit from such a program. For all other children general perception training may be sufficient.
\end{abstract}

Copyright $\odot 2008$ S. Karger AG, Basel

\begin{tabular}{ll}
\hline KARGER & ( ) 2008 S. Karger AG, Basel \\
Fax +4161306 12 34 & \\
$\begin{array}{l}\text { E-Mail karger@karger.ch } \\
\text { www.karger.com }\end{array}$ & $\begin{array}{l}\text { Accessible online at: } \\
\text { www.karger.com/fpl }\end{array}$
\end{tabular}

\section{Introduction}

During the 1980s several studies could demonstrate that phonological awareness is related to early reading and spelling abilities [cf. 1]. Phonological awareness consists of the recognition of rhymes and the number of syllables, as well as the differentiation and identification of phonemes. Lundberg et al. [2] found that a training of the phonological awareness in preschool children improves their ability to learn reading and writing. Schneider et al. [3] replicated the study of Lundberg et al. with German children who were about 1 year younger than the Danish children. Both Danish and German children are usually not taught reading and writing before school entrance. In both studies, a significant improvement of different parameters related to metalinguistic awareness was found directly after the training. Only when the training was conducted consistently did the children profit from the training for their reading and spelling ability [3].

In both studies tests of phonologic awareness and other metalinguistic variables were controlled, but the children were not checked for their hearing ability, the visual perception and multilingualism or language deficits.

In a secondary analysis of the same data, Schneider et al. [4] addressed the question whether children with ini-

A. Keilmann

Division of Communication Disorders, Department of ORL, Mainz Medical School Langenbeckstrasse 1, DE-55101 Mainz (Germany)

Tel. +496131 17 2190, Fax +496131176623

E-Mail keilmann@kommunikation.klinik.uni-mainz.de 
tially low levels of phonological awareness would benefit from the program. For both the level of phonological awareness and reading and spelling in school, the formerly weak children showed a better performance compared to the whole control group.

To our knowledge in all studies with preschool children, those in the intervention group were compared to children who were not treated. In our study, we used an unspecific training of the perception for the control group.

\section{Methods}

On the occasion of the introduction of a systematic training of the phonological awareness to the kindergartens in Wiesbaden, a prospective study, approved by the Ethics Committee RheinlandPfalz, was conducted. The participation was suggested to all children entering school the following year in the 19 kindergartens that took part in the study $(n=289)$. From 218 preschool children we got the parental consent and they took part in all the examinations before the beginning of the training. According to the intention of the public health department of Wiesbaden, the majority of them should be trained in phonological awareness. A smaller group was planned to be trained in another way in order to examine the specific effect of the training.

Their parents gave their informed consent and answered some anamnestic questions about pregnancy and birth, as well as hearing and language disorders.

Fifteen months before entering school, the ears, nose and throat of all children were examined; they passed pure tone audiometry, tympanometry, as well as speech audiometry in quiet and noise in the Department for Communication Disorders. The same day a nonverbal intelligence test (Colored Progressive Matrices [5]) was carried out. In kindergarten a speech therapist conducted a speech and language test. The mastery of grammatical structures was checked using a nonstandardized test (Ravensburger Dysgrammatiker-Material [6]) and compared to the classification by Clahsen [7]. The articulation was looked at with the 'Neuer Mainzer Lautstatus', a series of pictures the child is asked to name, and compared to the norms for German children given by Fox and Dodd [8]. The memory span for numbers ('Wiedergabe von Zahlenfolgen'), nonsense syllables ('Nachsprechen von Kunstwörtern') and meaningful sentences ('Nachsprechen von Sätzen') was determined using standardized tests from IDIS (Inventar diagnostischer Informationen bei Sprachentwicklungsauffälligkeiten [9]).

Twenty-seven children lived in multilingual settings. Five of them mastered both languages, 19 suffered from a delayed speech and language development and 3 children spoke their mother language normally but still had problems in German during the initial tests. These 3 children were added to the group of the normally speaking children.

The visual perception was checked using a short form of 'Frostigs Entwicklungstest der visuellen Wahrnehmung' (FEW) [10], a standardized test looking at different aspects of visual perception. One year before entering school the 'Bielefelder Screen- ing zur Früherkennung von Lese-Rechtschreibschwierigkeiten' (BISC) [11], a test to detect children at risk for reading and writing, was conducted. This test consists of 10 subtests, including those for the auditory memory span, for rhyming and syllable segmentation, and for visual comparison of letters and colors.

The children were randomized to the specialized training (ST) program for phonological awareness 'Hören, lauschen, lernen' [12] or to a more general perception training [alternative training (AT) [13]]. The temporal frame of the perception training was chosen similar to that of the phonological awareness program. Both programs were conducted 6 months during the last year before entering school by the kindergarten teachers, who were introduced to the program by the speech therapist. The training was written down by the kindergarten teachers. The speech therapist regularly visited the kindergartens in order to standardize the conduction of the training and to solve problems.

'Hören, lauschen, lernen' (ST [12]) included daily sessions of 6 metalinguistic exercise and game units: listening games including verbal and nonverbal sounds, identification of rhymes, spoken sentences and words, and syllable segmentation and analysis. In the second half, phonemes were introduced resulting in phoneme analysis and synthesis of more complex words in the last unit.

The 'Lernprogramm zur Wahrnehmungsförderung' (learning program for perception training) by Mertens [13] has no strict timetable. It begins with the perception of warmth, coldness and other characteristics of the environment, proceeds to the perception of physical conditions and relations to other persons. Different materials are used, all senses are included.

At the end of the first grade, 131 children could be tested for their reading and writing abilities using the 'Würzburger Leise Leseprobe' (WLL [14]) and the 'Hamburger Schreibprobe 1+' (HSP1+ [15]). These tests were conducted by the last author, mostly in the former kindergarten of the child. The parents were informed about all test results.

The results of the HSP are given in T scores and standard deviations, those of the WLL in percentiles and standard deviations.

We specially looked at 4 subgroups and compared them to the children without this problem.

\section{Ear and Hearing Problems}

Twenty-four children had suffered from ear and hearing problems before, 28 children had pathological middle ear findings, 8 an actual hearing loss of more than $20 \mathrm{~dB}$ and 36 a pathological tympanometric result at the beginning of the study.

Taken together all those (overlapping) groups, 57 children with peripheral hearing problems were compared to those who did not have those problems.

\section{Speech and Language Development}

Fifty-two children were not able to use the prepositional phrases or subordinate clauses or suffered from a severe language impairment. This group was also compared to the children with normal speech and language development.

\section{Reduced Memory Span for Nonword Repetition}

Twenty children did not reach the critical value defined for the repetition of nonwords as examined by 'Nachsprechen von Kunstwörtern' from IDIS [9]. 
Table 1. Comparison of the whole groups of children

\begin{tabular}{|c|c|c|c|c|}
\hline & & $\begin{array}{l}\text { Mean ST } \pm \text { SD } \\
(\mathrm{n}=109)\end{array}$ & $\begin{array}{l}\text { Mean AT } \pm S D \\
(n=22)\end{array}$ & $\mathrm{p}$ \\
\hline WLL (PR) & & $45.36 \pm 31.09$ & $42.73 \pm 24.58$ & 0.756 \\
\hline HSPG ( $\mathrm{T}$ value) & number of all correct letters & $49.13 \pm 9.01$ & $46.14 \pm 6.43$ & 0.263 \\
\hline HSPA (T value) & alphabetic strategy & $53.76 \pm 9.98$ & $52.41 \pm 8.09$ & 0.233 \\
\hline HSPR (T value) & correct words & $49.16 \pm 9.51$ & $46.09 \pm 7.05$ & 0.176 \\
\hline HSPO (T value) & orthographical strategy & $54.09 \pm 8.45$ & $48.36 \pm 7.35$ & 0.0347 \\
\hline
\end{tabular}

Comparing the whole groups of children after the ST $(n=109)$ and the AT $(n=22)$ in an analysis of covariance the test results differed significantly only in the orthographical strategy HSPO. In the 3 other tests there was a tendency in favor of the children after the ST. p for the effect of the training in the analysis of covariance (covariates: BISC result, IQ, memory span for nonsense syllables).

Visual Perception

Using the total value of the FEW, 44 children were classified as at risk for the visual perception (percentage rank $<25$ ). As problems in visual perception are also suspected to lead to problems in reading and writing, we compared them to children with good visual perception.

Elevated Risk for the Development of Reading and Spelling Problems in the BISC

Using the norms of the BISC 15 children were judged at risk for the development of reading and spelling problems.

The scores of the risk groups were compared with the control group mean using 1-way analysis of variance. We conducted an analysis of covariance in order to judge the influence of the kind of training on reading and writing as seen in the results of the WLL and the subtests of the HSP. 'Ear and hearing problems', 'speech and language problems', 'intelligence', 'memory span for nonword repetition', 'FEW' and 'BISC' were entered as covariates.

\section{Results}

Regarding the tests results before the beginning of the program the children randomized to the ST were slightly inferior regarding the nonverbal intelligence (106.6 vs. 110.5; Colored Progressive Matrices) and the memory span for nonsense syllables (PWN in BISC; 'Nachsprechen von Kunstwörtern' in IDIS) but slightly superior in all other parts of the BISC.

Apart from the better result in the subtest BISC PWN $(\mathrm{p}=0.039)$ of the children who later passed the AT, there were no significant differences between both groups.

Comparing the whole groups of children having passed 1 of the 2 programs, the children after the ST ( $\mathrm{n}=$ 109) reached slightly better mean values than the others (AT, $\mathrm{n}=22$ ) in reading (WLL PR $45.36 \pm 31.09$ compared to $42.73 \pm 24.58$ for the children after AT) and spelling

Specialised Training of Phonological Awareness in Every Preschool Child?
Table 2. Number of subjects in the subgroups

\begin{tabular}{ll} 
Study population & \\
\hline Whole group & 131 \\
ST/AT & $109 / 22$ \\
Mono-/bilingual & $27 / 102$ \\
Hearing problems/not & $57 / 74$ \\
Speech and language problems/not & $52 / 79$ \\
At risk in the BISC/not & $22 / 109$ \\
\hline
\end{tabular}

(HSP), but only the difference in using orthographical strategy was significant (table 1 ).

Table 2 gives the number of subjects in the different subgroups.

\section{Ear and Hearing Problems}

The children who underwent the ST reached nearly normal values in all reading and writing tests independently of their hearing history. The GLM procedure demonstrated that those who had hearing problems and followed the AT scored worse than the others in reading $(p=0.0482)$. Detailed test results are given in table 3.

\section{Speech and Language Development}

The children who were not able to use prepositional phrases or subordinate clauses or suffered from a severe language impairment $(n=52)$ were compared to those with normal speech and language abilities. Thirteen children with an isolated stigmatism did not demonstrate deficits in reading and writing and were included in the normal group. The children with speech and language development problems reached slightly worse results in 
Table 3. Ear and hearing problems

\begin{tabular}{|c|c|c|c|c|c|}
\hline \multicolumn{3}{|c|}{ Training } & \multirow{2}{*}{$\begin{array}{l}\text { Hearing loss } \\
45.57 \pm 29.95\end{array}$} & \multirow{2}{*}{$\begin{array}{l}\text { Normal children } \\
45.19 \pm 32.17\end{array}$} & \multirow{2}{*}{$\begin{array}{l}\mathrm{p} \\
0.0482\end{array}$} \\
\hline WLL & ST & $(\mathrm{PR})$ & & & \\
\hline & $\mathrm{AT}$ & & $28.30 \pm 13.12$ & $54.75 \pm 25.81$ & \\
\hline \multirow[t]{2}{*}{ HSPG } & ST & number of all correct letters ( $\mathrm{T}$ value) & $49.70 \pm 8.96$ & $48.69 \pm 9.29$ & 0.2440 \\
\hline & AT & & $44.20 \pm 6.32$ & $47.75 \pm 6.32$ & \\
\hline \multirow[t]{2}{*}{ HSPA } & ST & alphabetic strategy (T value) & $54.53 \pm 9.83$ & $53.17 \pm 10.12$ & 0.8520 \\
\hline & $\mathrm{AT}$ & & $52.80 \pm 8.28$ & $52.08 \pm 8.27$ & \\
\hline \multirow[t]{2}{*}{ HSPR } & ST & correct words (T value) & $49.62 \pm 9.42$ & $48.81 \pm 9.64$ & 0.7064 \\
\hline & $\mathrm{AT}$ & & $45.70 \pm 7.48$ & $46.42 \pm 6.99$ & \\
\hline \multirow{2}{*}{ HSPO } & ST & orthographical strategy (T value) & $54.09 \pm 7.45$ & $55.10 \pm 9.19$ & 0.3669 \\
\hline & AT & & $46.50 \pm 7.83$ & $49.92 \pm 6.87$ & \\
\hline
\end{tabular}

Comparing the children with hearing problems (47 with ST, 10 with AT) to those without hearing problems (62 with ST, 12 with AT) after the ST and the AT the test results differed significantly only in the WLL. Mean values \pm standard deviation. $\mathrm{p}$ for the effect of the training in the analysis of covariance (covariates: BISC result, IQ, memory span for nonsense syllables).

Table 4. Speech and language development

\begin{tabular}{llllll}
\hline \multirow{2}{*}{ Training } & & & $\begin{array}{l}\text { Speech and } \\
\text { language problems }\end{array}$ & $\begin{array}{l}\text { Normal } \\
\text { children }\end{array}$ & $p$ \\
\hline WLL & ST & (PR) & $38.5 \pm 28.93$ & $50.00 \pm 31.85$ & 0.7888 \\
& AT & & $36.75 \pm 16.75$ & $46.14 \pm 28.12$ & \\
\multirow{2}{*}{ HSPG } & ST & number of all correct letters (T value) & $47.27 \pm 9.98$ & $50.39 \pm 8.88$ & 0.5831 \\
& AT & & $45.38 \pm 6.02$ & $46.57 \pm 6.84$ & \\
\multirow{2}{*}{ HSPA } & ST & alphabetic strategy (T value) & $52.23 \pm 10.11$ & $54.80 \pm 9.83$ & 0.7664 \\
& AT & & $51.38 \pm 10.81$ & $53.00 \pm 6.46$ & \\
\multirow{2}{*}{ HSPR } & ST & correct words (T value) & $47.50 \pm 9.25$ & $50.28 \pm 9.59$ & 0.7784 \\
& AT & & $45.00 \pm 6.68$ & $46.71 \pm 7.43$ & \\
HSPO & ST & orthographical strategy (T value) & $52.66 \pm 7.53$ & $55.06 \pm 8.94$ & 0.1742 \\
& AT & & $50.13 \pm 5.41$ & $47.36 \pm 8.26$ & \\
\hline
\end{tabular}

Comparing the children with speech and language problems (44 with ST, 8 with AT) to those without speech and language problems (65 with ST, 44 with AT) after the ST and the AT, the GLM procedure indicated neither an effect of the speech and language ability nor of the training, although most test results were lower in the speech and language group compared to the rest. Mean values \pm standard deviation. $p$ for the effect of the training in the analysis of covariance (covariates: BISC result, IQ, memory span for nonsense syllables).

reading and writing after both programs, but the analysis of covariance verified no influence of the speech and language status and the training modality. The test results are given in table 4.

\section{Reduced Memory Span for Nonword Repetition}

Twenty-two children did not reach the critical value defined for the repetition of nonwords, only one of them got the AT. The analysis of covariance gave no clear result, but there was no indication of influence.

\section{Visual Perception}

Using the total value of the FEW, 45 children were classified as at risk for the visual perception (percentage rank <25). Those children as a whole group later demonstrated slightly poorer reading abilities; an influence of the training modality was not seen. The children with problems in visual perception had no problems in writing. 
Table 5. Risk for the development of reading and spelling problems in the BISC

\begin{tabular}{llllll}
\hline Training & & & $\begin{array}{l}\text { At risk in } \\
\text { the BISC }\end{array}$ & $\begin{array}{l}\text { No risk in } \\
\text { the BISC }\end{array}$ & p \\
\hline WLL & ST & (PR) & $34.72 \pm 19.56$ & $46.55 \pm 31.98$ & 0.3474 \\
& AT & & $31.25 \pm 17.29$ & $45.28 \pm 25.61$ & \\
HSPG & ST & number of all correct letters (T value) & $43.18 \pm 9.26$ & $49.80 \pm 8.78$ & 0.0148 \\
& AT & & $39.50 \pm 5.69$ & $47.61 \pm 5.72$ & \\
HSPA & ST & alphabetic strategy (T value) & $48.36 \pm 13.22$ & $54.37 \pm 9.44$ & 0.0022 \\
& AT & & $40.75 \pm 5.50$ & $55.00 \pm 6.03$ & \\
HSPR & ST & correct words (T value) & $44.82 \pm 9.54$ & $49.64 \pm 9.43$ & 0.0289 \\
& AT & & $39.00 \pm 6.73$ & $47.67 \pm 6.24$ & \\
HSPO & ST & orthographical strategy (T value) & $49.82 \pm 7.72$ & $54.57 \pm 8.43$ & 0.0872 \\
& AT & & $44.00 \pm 7.26$ & $49.33 \pm 7.21$ & \\
\hline
\end{tabular}

Comparing the children who were at risk in the BISC (18 with ST, 4 with AT) to those without risk (98 with ST, 11 with AT) after the ST and the AT, the GLM procedure indicated an effect of the BISC result on HSPG, HSPA and HSPR, a slight effect on HSPO but not on reading as seen in the WLL. p for the group (at risk or not at risk in the BISC) in the analysis of covariance (covariates: IQ, memory span for nonsense syllables).

\section{Elevated Risk for the Development of Reading and} Spelling Problems in the BISC

Using the BISC, 22 children were judged at risk for the development of reading and spelling problems. Eighteen children were phonologically trained, 4 with the general perception training. The children at risk in the BISC scored worse in the spelling tests (significant in HSPG, HSPA and HSPR) at the end of the first grade, with no differences related to the type of training. The test results for all 4 groups are given in table 5 .

\section{Discussion}

In our study we compared 2 groups of children having passed 1 of the 2 programs, an ST $(n=109)$ and a more general perception training $(\mathrm{AT}, \mathrm{n}=22)$ during their last year of kindergarten.

Previous studies of the effect of the specialized program 'Hören, lauschen, lernen' [12] compared groups of trained children to untrained children $[3,4]$. In our study we used alternative general perception training with the same temporal frame for the control group in order to find the specific effect of the ST.

On average after ST the children reached slightly better values in reading and spelling, but most differences were not statistically significant. Only the difference in using the orthographical strategy reached statistical significance, although the training should not influence this

Specialised Training of Phonological Awareness in Every Preschool Child? ability, as the children were not confronted with letters and orthographic rules [12]. As the training kindergarten teachers were instructed in great detail, the conduction of the training was carefully watched and taken down, mainly the small number of children per subgroup must be considered as a limiting factor. Furthermore, the small difference between the 2 intervention groups can be explained partially by the limited influence of the phonological awareness on the abilities in reading and spelling. In a study with 70 kindergarten children followed until the middle of grade 2 , only $13 \%$ of the variance of sentence reading was explained by phonological awareness in [16]. Other strong candidates for improving the prognosis could be automatic naming, the rate of acquisition of phonological awareness, beginning readers' motivational tendencies and coping patterns under stress [17].

Most studies dealing with supportive measures of the phonological awareness focus on children of the first grade [18]. For these studies, Bus and van Ijzendoorn [18] deduce that phonological awareness is an important but not a sufficient condition for early reading. The training effects were stronger with posttests assessing simple decoding skills than with real-word identification tests.

Cunningham [19] and Hatcher et al. [20] argued that training of the phonological awareness in isolation from reading and spelling may be much less effective than with first graders who are learning to read. In the version we used in our study the children were not confronted with letters. 
In contrast to the former studies of the ST, we also controlled the hearing ability, language deficits, the visual perception or the test result in the BISC. Looking at different groups of children, we found weaker results in reading and writing in the children who had ear and hearing problems, speech and language impairment, a reduced memory span for nonsense syllables or were at risk following the BISC. Comparing the 2 modes of training only children with ear and hearing problems profited more from the ST program compared to the general perception training for reading.

Bishop and Adams [21] assessed the language and literacy skills in 8.5-year-old children who had been diagnosed as having specific language impairment at 4 years of age. Only in the children who still had language problems by the age of 5.5 years were reading difficulties present. Mostly reading comprehension was poor compared to reading accuracy. Only weak links were found between expressive phonological disorders and the later ability to read.

Leitao and Fletcher [22] presented follow-up data of 2 subgroups of formerly speech-impaired children. They were divided into a group with developmental and one with nondevelopmental speech errors. They found that only the last group showed persisting reading and spelling difficulties at the age of 12-13 years. Recently, Rvachew examined relationships among the children's prekindergarten performance on measures of speech perception, vocabulary, articulation and phonological awareness skills. Articulation accuracy prior to kindergarten did not predict phonological awareness at the end of kindergarten. Speech perception prior to kindergarten explained $11 \%$ and receptive vocabulary prior to kindergarten $10 \%$ of the variance in phonological awareness at the end of kindergarten [23].

Marx et al. [24] reported on the training of children attending special preschools for children with speech and language problems. Children with deficits in grammar and vocabulary performed worse in the tasks of phonological awareness than children without such deficits. Directly after the training the phonological awareness was ameliorated, but the stability of the effects and the transfer on the acquisition of literacy was not yet shown. Hesketh [25] reported about assessment of phonological awareness, speech and early literacy in 35 children who had been treated because of a moderate to severe speech disorder between the ages of 3.5 and 5 years. Most children with an isolated speech disorder achieved normal early literacy. Hesketh advises to assess phonological awareness in these children in order to identify those who are at risk even after speech intervention.

The missing specific effect for the children at risk following the BISC is in clear contrast to the results of Schneider et al. [4], who found that children with initially low levels of phonological awareness showed a better performance compared to the whole control group.

These results may partly be due to the small number of children in the groups and to the big variance in the test results. Another explanation may be that the children at risk profit from different modes of intervention so that an ST of the phonological awareness must not be superior to another meaningful program.

\section{Conclusion}

In our study we could not prove the necessity of an ST program to improve phonologic awareness as a basis for reading and writing in every kindergarten and preschool child. However, children with temporary hearing problems benefited from such a program. A general perception training or other purposeful measures to ameliorate attention and the ability to work may be sufficient.

\section{References}

1 Bradley L, Bryant P: Rhyme and Reason in Reading and Spelling. Ann Arbor, University of Michigan Press, 1985.

$\checkmark 2$ Lundberg I, Frost J, Petersen OP: Effects of an extensive program for stimulating phonological awareness in preschool children. Read Res Q 1988;23:261-284.

$\checkmark 3$ Schneider W, Küspert P, Roth E, Visé M: Short- and long-term effects of training phonological awareness in kindergarten: evidence from two German studies. J Exp Child Psychol 1997;66:311-340.
-4 Schneider W, Roth E, Küspert P, Ennemoser M: Kurz- und langfristige Effekte eines Trainings der sprachlichen (phonologischen) Bewusstheit bei unterschiedlichen Leistungsgrupppen: Befunde einer Sekundäranalyse. Z Entwicklungspsychol Pädagog Psychol 1998;30:26-39.

5 Schmidtke A, Schaller S, Becker P: Raven Matrizen Test. Coloured Progressive Matrices (CPM). Weinheim, Beltz, 1980.

6 Frank G, Grziwotz P: DysgrammatikerPrüfmaterial. Ravensburg, Sprachheilzentrum, 1978. 
7 Clahsen H: Die Profilanalyse. Ein linguistisches Verfahren für die Sprachdiagnose im Vorschulalter. Berlin, Marhold, 1986.

8 Fox AV, Dodd BJ: Der Erwerb des phonologischen Systems in der deutschen Sprache. Sprache Stimme Gehör 1999;23:183-191.

9 Schöler H: IDIS - Inventar diagnostischer Informationen bei Sprachentwicklungsauffälligkeiten, ed S. Heidelberg, Universitätsverlag Winter, 1999.

10 Lockowandt O: Frostigs Entwicklungstest der visuellen Wahrnehmung. Weinheim, Beltz, 1993.

11 Jansen H, Mannhaupt G, Marx H, Skowronek H: Bielefelder Screening zur Früherkennung von Lese-Rechtschreibschwierigkeiten (BISC). Göttingen, Hogrefe, 1999.

12 Küspert P, Schneider W: Hören, lauschen, lernen. Sprachspiele für Kinder im Vorschulalter, ed 2. Göttingen, Vandenhoek \& Ruprecht, 2000.

13 Mertens K: Lernprogramm zur Wahrnehmungsförderung. Dortmund, Verlag Modernes lernen, 1988.
14 Küspert P, Schneider W: Würzburger Leise Leseprobe. Göttingen, Hogrefe, 1998.

15 May P: Hamburger Schreib-Probe (HSP1+), ed 5. Hamburg, Verlag für pädagogische Medien, 1998.

16 Sprigevica A, Hoien T: Early phonological skills as a predictor of reading acquisition: a follow-up study from kindergarten to the middle of grade 2. Scand J Psychol 2003;44: 119-124.

17 Niemi P, Poskiparta E: Shadows over phonological awareness training: resistant learners and dissipating gains; in Hjelmquist $\mathrm{E}$, von Euler C (eds): Dyslexia and Literacy. London, Whurr, 2002, pp 84-99.

18 Bus AG, van Ijzendoorn MH: Phonological awareness and early reading: a meta-analysis of experimental training studies. J Educ Psychol 1999;91:403-414.

19 Cunningham A: Explicit versus implicit instruction in phonemic awareness. J Exp Child Psychol 1990;50:429-444.
20 Hatcher PJ, Hulme C, Ellis AW: Ameliorating early reading failure by integrating the teaching of reading and phonological skills: the phonological linkage hypothesis. Child Dev 1994;65:41-47.

21 Bishop DVM, Adams C: A prospective study of the relationship between specific language impairment, phonological disorders and reading retardation. J Child Psychol Psychiatry 1990;31:1027-1050.

22 Leitao S, Fletcher J: Literacy outcomes for students with speech impairment: long-term follow-up. Int J Lang Commun Disord 2004; 39:245-256.

23 Rvachew S: Longitudinal predictors of implicit phonological awareness skills. Am J Speech Lang Pathol 2006; 15:165-176.

24 Marx P, Weber J, Schneider W: Phonologische Bewusstheit und ihre Förderung bei Kindern mit Störungen der Sprachentwicklung. Z Entwicklungspsychol Pädagog Psychol 2005;37:80-90.

25 Hesketh A: Early literacy achievement of children with a history of speech problems. Int J Lang Commun Disord 2005;39:453468. 